Revista Destaques Acadêmicos, Lajeado, v. 12, n. 4, 2020. ISSN 2176-3070

DOI: http://dx.doi.org/10.22410/issn.2176-3070.v12i4a2020.2759

http://www.univates.br/revistas

\title{
AUTOM8 - FERRAMENTA WEB PARA GERENCIAMENTO, MANUTENÇÃO E ATUALIZAÇÃO REMOTA DE SISTEMAS OPERACIONAIS E APLICATIVOS
}

\author{
Heryk Gasparini ${ }^{1}$, Fabrício Pretto ${ }^{2}$
}

Resumo: A gestão e o controle das estações de rede segundo os conceitos da governança da TI e da gerência de redes de computadores, permitem a uma organização alcançar maior eficiência na gestão de recursos de TI. As soluções disponíveis no mercado para o gerenciamento de estações de rede por meio de um software possuem um alto valor financeiro. A necessidade de manutenção de software e hardware é frequente e exige monitoramento e correções de falhas. $\mathrm{O}$ gerenciamento remoto permite aos profissionais e departamentos de TI realizar manutenções preventivas e corretivas de forma eficiente. Este trabalho apresenta o desenvolvimento de uma ferramenta composta por uma aplicação web, chamada de gerente, e uma aplicação cliente, instalada nas estações atuando como um agente de rede para realizar a comunicação entre os sistemas. O intuito do desenvolvimento da solução é otimizar os recursos e processos de gerenciamento, manutenção e atualização remota de software operacional e aplicativo de estações de rede. A solução desenvolvida permite fazer a gestão de estações de rede de forma remota e eficiente. Através do acompanhamento dos registros e criação de tarefas automatizadas, a aplicação web coordena a execução na aplicação cliente instalada nas estações de rede.

Palavras-chave: Governança da tecnologia da informação. Gerência de redes. Software.

\section{INTRODUÇÃO}

Nos dias atuais a tecnologia da informação é um recurso com cada vez mais importância para as organizações, estando mais ligada aos processos organizacionais. Conforme os autores Weill e Ross (2006), devido ao crescimento da sua importância, novas soluções administrativas são difundidas com o intuito de estimular as boas práticas para a gestão dos recursos para a estruturação da Tecnologia da Informação nas organizações públicas e privadas. Como exemplo, as boas práticas de Governança da Tecnologia da

1 Engenheiro da Computação - Univates - heryk07@universo.univates.br

2 Mestre em Ciência da Computação - Univates - fabricio.pretto@univates.br 
Informação influenciam nas decisões de TI e nos objetivos de desempenho da corporação.

O uso de recursos de TI nas organizações é uma realidade evidente que não depende do tamanho e do número de colaboradores. A tecnologia tornou-se uma condição de disputa e qualificação das ferramentas de trabalho, proporcionando o acesso a ferramentas organizacionais que gerenciam as atividades das empresas.

Segundo Tanenbaum (1997), as empresas de grande porte possuem um grande número de estações em seu domínio de trabalho conectados à uma rede local com o intuito de permitir que as informações possam ser compartilhadas, mesmo estando fisicamente distantes. Para Spezia (2007), é necessário que a organização faça o gerenciamento destes recursos, para poder assim garantir a sua melhor gestão, e também que possa atender às necessidades individuais de cada estação de rede.

Devido ao número de estações computacionais em uma organização, seja ela de pequeno ou grande porte, soluções de software foram desenvolvidas para apoiar a atividade de gerenciamento, ou seja, sistemas para realizar a gestão destes computadores de forma remota, ganhando assim efetividade no gerenciamento, manutenção e atualização dos mesmos.

O tema de estudo reflete-se no desenvolvimento de uma ferramenta web relacionada às áreas da governança da tecnologia da informação e do gerenciamento de redes de computadores, focada no controle de manutenção de software operacional e aplicativo de estações de rede.

As ferramentas de controle e monitoramento remoto são utilizadas para manutenção de TI em nível organizacional, com recursos de gestão da tecnologia de uma grande corporação para pequenas e médias empresas, beneficiando também os departamentos de TI com a utilização desse tipo de solução. A gestão de estações de rede por meio de um software possui alto valor financeiro para a manutenção da ferramenta em médias e pequenas empresas, devido à existência de soluções robustas e consolidadas no mercado.

O presente trabalho tem como objetivo geral desenvolver uma solução para o gerenciamento, manutenção e atualização remota de sistemas de operação e aplicativos que facilitem e otimizem os processos de trabalho de profissionais e departamentos de TI.

\section{REFERENCIAL TEÓRICO}

Como referencial teórico são apresentados conceitos relacionados à Governança de TI e Infraestrutura de serviços. 


\subsection{Governança da tecnologia da Informação}

Para Thompson-Flôres (2004), a GTI (Governança de Tecnologia da Informação) é a parte que integra a Governança Corporativa, onde relaciona-se com a administração, conselho e partes interessadas de uma empresa, visando a garantia de retorno dos investimentos realizados pelos acionistas.

De acordo com Assis (2011), a expressão governança de TI tem sido muito utilizada, entretanto com conceitos diferentes na literatura especializada: adesão de melhores práticas, gestão de riscos, gestão de projetos, relação com governança corporativa. Os conceitos apresentam abordagens distintas, conforme o objetivo do pesquisador ou da abordagem da pesquisa dificultando assim o entendimento do tema. Albertin e Albertin (2005) complementam que a governança de TI relaciona-se diretamente com a autoridade e a responsabilidade pelas medidas relacionadas ao uso da Tecnologia da Informação e sua administração na organização.

Segundo afirmação exposta por Weill e Ross (2004), a GTI é um mecanismo organizacional que assegura que as estratégias da Tecnologia da Informação serão atendidas de forma adequada, por meio da capacitação da organização em aspectos de gestão da tecnologia, da promoção de formas para auxiliar na tomada de decisões sobre mecanismos de controle e investimentos, gerando maior eficiência aos negócios das instituições.

Conforme o IT Governance Institute (ITGI), a GTI engloba e reconhece as boas práticas para planejar e organizar, implantar, dar suporte, monitorar e efetuar a avaliação do desempenho, de modo a garantir que a informação e a tecnologia associada ajudem a empresa a alcançar seus objetivos. A governança de TI capacita as organizações a tirar ganho de sua informação, aumentando os benefícios e a vantagem competitiva. Também identifica as fraquezas de controle e garante a implementação eficiente de melhorias mensuráveis (ITGI, 2007).

Para Picada (2006) a Governança de TI busca permitir que as perspectivas de negócios, de infraestrutura, de pessoas sejam levadas em consideração no momento de definição dos interesses da organização, alinhando TI à sua estratégia. Conforme Rodrigues (2006), podemos definir as seguintes vantagens que a governança de TI traz para as empresas: Torna evidente a relação entre os custos de TI e as necessidades de negócio; Colabora para manter os riscos do negócio sob controle; Evidencia a importância da TI na continuidade dos negócios; e Mede e melhora constantemente a performance de TI.

\subsection{Gerenciamento da Configuração e de Ativo de Serviço}

Segundo Silva (2009) pode-se estabelecer como objetivo principal do Gerenciamento de Configuração a criação de um modelo lógico da infraestrutura de TI, realizando a identificação, controle, registro, auditando e verificando os itens de configuração dos serviços, por exemplo, versões de 
softwares, componentes, garantias e validades de serviços. Também fazem parte do processo os ativos de informação, como por exemplo: planos, business cases, especificações de serviços, entre outros.

Para prover as informações precisas aos outros processos do ITIL são necessárias a criação e a manutenção de uma Base de Dados do Gerenciamento da Configuração (BDGC). Essa base é um repositório de informações onde são armazenadas as informações relativas aos itens de configuração (IC). Seu objetivo é otimizar a performance dos ativos de serviço e das configurações, para otimizar os riscos e os custos (SILVA, 2009).

Para cada IC cadastrado na base de dados, deve ser atribuído um código único de identificação. Além do código, outros dados podem ser cadastrados como tipo, versão, localização, status etc., e os procedimentos de controle destes ICs (SILVA, 2009).

\subsection{Gerência de Redes de Computadores}

Segundo Avalle (1996) o gerenciamento de redes está diretamente associado ao monitoramento de utilização dos recursos de rede e ao controle de atividades. As funções básicas de gestão de redes são: obter relatórios da rede e tratar estes relatórios para que se possibilite um diagnóstico já encaminhando as soluções de problemas. Para isso, funções de gerenciamento devem ser introduzidas nos diversos elementos de uma rede, para que seja possível prever, descobrir e agir sobre as falhas.

De acordo com o autor Carvalho (1993), a função de gerenciamento de redes baseia-se em administrar e monitorar os múltiplos ativos em uma rede, sejam ativos lógicos ou ativos físicos e assim manter um nível adequado de QoS (Quality of Service). Entretanto com o grande crescimento em diversidade e números das redes e de seus elementos essa atividade tem sido cada vez mais complexa. Ainda de acordo com Carvalho (1993) a realização de testes dos problemas e o isolamento das redes têm sido difíceis devido às duas principais causas: i) distintos níveis de pessoas envolvidas, tais como, controladores e operadores de rede, administradores de sistemas de informação, técnicos de manutenção; ii) diferentes formas de monitoramento e controle de redes.

Ainda conforme Carvalho (1993), uma estrutura manual de gerência de redes baseada em papel só se torna funcional quando a dimensão da rede é relativamente pequena, já em uma rede maior estruturada esse sistema é incapaz de registrar o universo dos incidentes.

Segundo Mendes (2007), logo que a TI começou a ser parte importante das instituições e organizações de modo geral, também surgiu a exigência de uma gestão das estações de rede nela presentes. A área do gerenciamento de redes foi inicialmente impulsionada pela necessidade de monitoração e controle do conjunto de estações que fazem parte das redes de comunicação. Nos dias atuais, as redes de computadores associadas aos seus recursos, além 
das aplicações distribuídas, têm tornando-se essencial e de tal relevância para uma instituição ou organização que, de modo geral elas não podem falhar.

Segundo Kurose e Ross (2006) para realizar a padronização a administração de redes, a ISO realizou a classificação das áreas funcionais da gestão de redes em cinco categorias: i) gerenciamento de desempenho, que é responsável por medir, quantificar, analisar, informar e realizar o controle do desempenho de diferentes elementos na rede; ii) gerenciamento de falhas tem como objetivo a detecção e reação às condições de falhas que transitam na rede; iii) gerenciamento de configuração que permite ao administrador saber quantos e quais estações que contemplam o ambiente por ele gerenciado e quais são as configurações de software e hardware; iv) gerenciamento de contabilização possibilita que um gestor de redes defina, registre e controle o acesso de usuários e estações aos recursos da rede; v) gerenciamento de segurança que propõe-se a controlar o acesso aos ativos de rede conforme políticas já especificadas.

$\mathrm{O}$ gerenciamento de rede permite ao administrador, encarregado pelo seu funcionamento, ter uma visão precisa e detalhada do que está ocorrendo em tempo real nos ativos presentes na topologia da rede, onde é possível detectar precocemente algum evento que esteja fugindo da rotina e que possa causar prejuízos no futuro. Permite o uso de ações preventivas ao invés de apenas corretivas, ou seja, possibilita corrigir os erros antes de que prejudiquem a qualidade da rede.

\subsection{Arquitetura de gerenciamento de redes}

Para Tanenbaum (2003), os sistemas de informação de uma organização ou instituição consistem em bancos de dados e de colaboradores que necessitam realizar o acesso a estas informações de forma remota. Nesse padrão, os dados são armazenados em super computadores chamados servidores. Em seguida, essas máquinas poderosas são instaladas e mantidas em um lugar centralizado por um gerente de redes ou administrador de sistemas. Oposto a isso, os colaboradores têm em sua área de trabalho computadores mais comuns, chamados clientes, com as quais eles acessam as informações de forma remota, como por exemplo, para inserir dados em planilhas colaborativas.

Toda essa combinação chama-se modelo cliente/servidor. Ele é amplamente utilizado e compõe a base da vasta utilização da rede. Aplicase esse modelo quando servidor e cliente estão os dois no mesmo local (por exemplo, pertencem à mesma organização ou instituição), mas também quando se encontram muito distantes um do outro (TANENBAUM, 2003). Como por exemplo, quando um indivíduo em seu domicílio acessa uma página na internet, é empregado o mesmo modelo, com o servidor da página Web remota fazendo a função do servidor e a máquina pessoal do usuário sendo o cliente. Sob a maior parte das situações, um único servidor pode atender um grande número de clientes. 
Ainda segundo Tanenbaum (2003), se observarmos a representação cliente/servidor em detalhes, veremos que há dois processos compreendidos, um no computador cliente e outro no computador servidor. A comunicação assume a forma do processo do computador cliente enviando uma comunicação pela rede ao processo da máquina servidor. Portanto, o processo do computador cliente aguarda por uma mensagem de resposta. Quando o processo da máquina servidor recebe o pedido, ela executa a tarefa solicitada ou busca pelos dados requisitados e retorna uma resposta.

\section{METODOLOGIA}

O método de pesquisa adotado para o trabalho foi o indutivo, seguindo Lakatos e Marconi (2003), o método indutivo chega em conclusões prováveis fundamentadas em premissas. $\mathrm{O}$ método indutivo foi imposto ao projeto devido à natureza do raciocínio sucessivo do tema exposto, onde há a análise geral até a particular para verificação da hipótese e a conclusão dos objetivos propostos.

O modo de abordagem da pesquisa adotado para o trabalho foi qualitativo, pois para Neves (2015), a pesquisa qualitativa se preocupa com a análise subjetiva dos dados pesquisados e não com sua quantidade, sendo assim possível entender qual propósito do objeto de pesquisa.

A metodologia quanto ao objetivo deste trabalho foi a exploratória, pois para Gil (2010), as pesquisas exploratórias visam proporcionar uma maior familiaridade com o problema em questão, para torná-lo explícito ou criar hipóteses. Portanto, é necessário um levantamento bibliográfico, entrevistas com especialistas e análise de exemplos. Segundo os objetivos do presente trabalho, que é projetar uma ferramenta para gerenciamento, manutenção e atualização de softwares operacionais e aplicativos, envolvendo os conceitos de governança da tecnologia da informação e gerência de redes, adotou-se a pesquisa exploratória para a busca dos conceitos envolvidos.

A metodologia quanto ao procedimento técnico empregado ao trabalho foi a pesquisa bibliográfica, que conforme Gil (2002) a pesquisa bibliográfica é composta por livros e artigos científicos, fundamentadas em materiais já criados. O trabalho vai de encontro ao procedimento devido ao estudo de materiais e registros reconhecidos e existentes para apresentação da proposta e do desenvolvimento da referida solução.

Além da pesquisa bibliográfica, outro procedimento técnico utilizado foi a pesquisa experimental devido ao trabalho ser o desenvolvimento de uma solução, que de acordo com Gil (2002) a pesquisa experimental determina-se o objeto a ser estudado e seleciona-se variáveis que atuam nele, podem assim analisar os efeitos ocorridos no mesmo. 


\subsection{Tecnologias}

A solução utilizou-se o PHP para desenvolvimento da aplicação web no lado do servidor juntamente com o Adianti Framework, que oferece um conjunto de componentes para facilitar a implementação do software, assim otimizando o processo de desenvolvimento.

O banco de dados utilizado para o desenvolvimento da solução foi PostgreSQL atuando ao lado do servidor da aplicação web, a escolha deuse devido aos conhecimentos prévios do uso tecnologia e por atender as necessidades.

Utilizou-se a linguagem Java para desenvolvimento do sistema no lado do cliente e a escolha por esta linguagem deu-se pelo fato dela ter possibilitado construir aplicações multiplataformas, essencial no desenvolvimento do projeto para alcançar proposta inicial do trabalho de executar em ambientes operacionais Windows e Linux.

\section{EXPERIMENTAÇÃO}

A solução denominada AutoM8 possui o foco na criação, aplicação e controle de tarefas automatizadas conforme título da ferramenta, ou seja, scripts, de modo que a criação dos scripts possua um template, ou seja, modelo de script para reutilização de código, ganhando eficiência nos processos de gestão. Estes scripts podem ser aplicados a um único dispositivo ou a um grupo de estações de rede. A ferramenta também contempla um controle da execução destas tarefas automatizadas, informando os detalhes da execução do script separado por dispositivo, facilitando a visualização dos problemas de forma isolada por dispositivo.

\subsection{Arquitetura}

No sistema web são mantidos os cadastrados de rótulos de dispositivos, cadastro de dispositivos, cadastro de softwares para auxiliarem a manutenção dos cadastros de tarefas e de scripts. O servidor da aplicação web contempla o repositório de arquivos, onde o sistema gerencia os arquivos mantidos pelo sistema web.

O webservice tem como função disponibilizar as tarefas aos sistemas clientes, além de receber as informações da situação das tarefas da aplicação cliente e manter o registro dessas informações no banco de dados.

O sistema cliente possui o papel de gerenciar e executar no sistema operacional da estação de rede as tarefas destinadas pela aplicação principal. A aplicação cliente tem como responsabilidades: requisitar se há novas tarefas no webservice; identificar o sistema operacional e o endereço físico da placa de rede da estação cliente; requisitar, executar e controlar a tarefa mantendo os detalhes da tarefa localmente no dispositivo até o término da execução; 
além de enviar a situação de cada tarefa ao webservice. A Figura 1 apresenta a arquitetura da ferramenta AutoM8.

Figura 1 - Arquitetura do AutoM

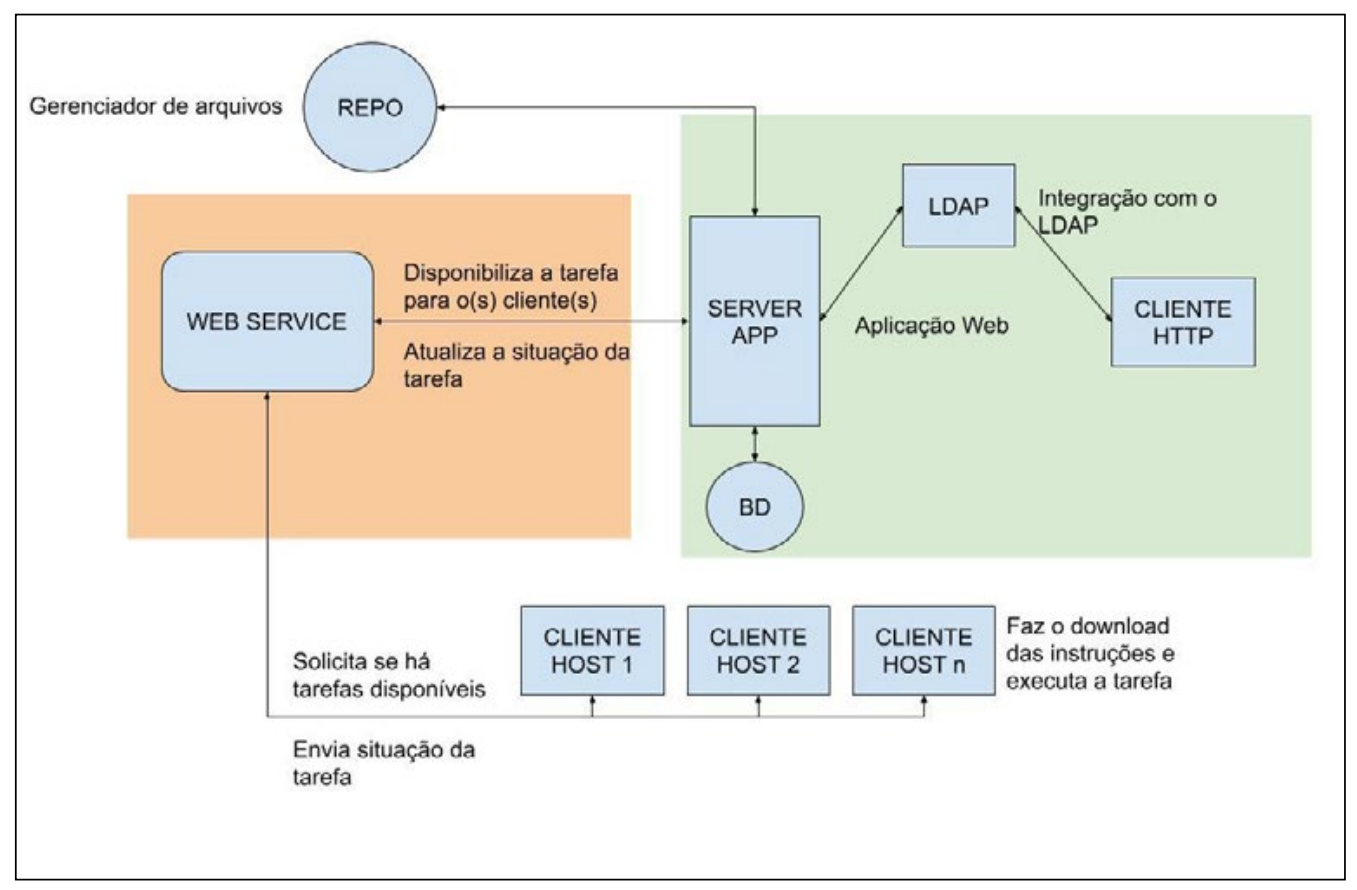

Fonte: Do autor (2020).

\subsection{Modelo entidade relacionamento}

Nesta seção podem ser observados três modelos de entidade relacionamento. Isso ocorre pois durante o processo de desenvolvimento da solução, realizou-se o reaproveitamento do que já é oferecido pela ferramenta de desenvolvimento dividindo o escopo de informações em três partes: 1) Aplicação; 2) Logs; 3) Permissões.

Na Figura 2 é possível visualizar o primeiro dos três modelos ER, responsável por armazenar os dados da aplicação principal. As principais entidades a serem observadas são: job, device e script, elas correspondem ao cerne da aplicação AutoM8.

Na Figura 3 pode-se visualizar três entidades responsáveis por armazenar os logs gerados no sistema web. A primeira tabela "system_access_ log" mantém os dados de acesso à aplicação. A segunda tabela "system_sql_ log" armazena todos as instruções enviadas para o banco de dados. A terceira tabela "system_change_log" armazena todo o histórico de alteração dos registros, contendo os valores novos e os antigos. 
Figura 2 - Modelo entidade relacionamento - Aplicação

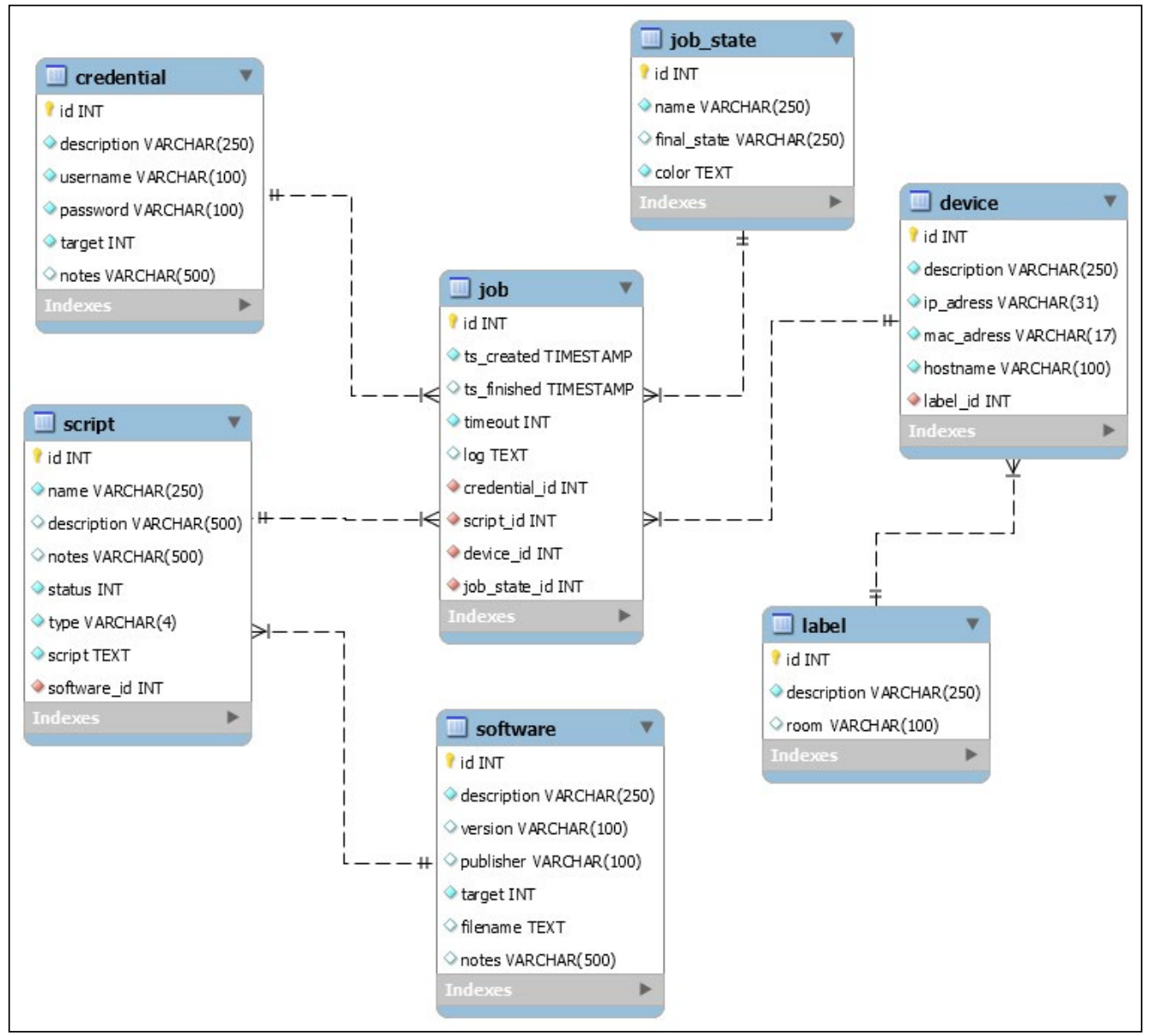

Fonte: Do autor (2020). 
Figura 3 - Modelo entidade relacionamento - Log



Fonte: Do autor (2020).

O terceiro modelo ER é o responsável por armazenar os dados administrativos da solução. Ou seja, este modelo representa as entidades que armazenam os cadastros de usuários e permissões. A Figura 4 exibe a modelagem do banco. 
Figura 4 - Modelo entidade relacionamento - Permissões

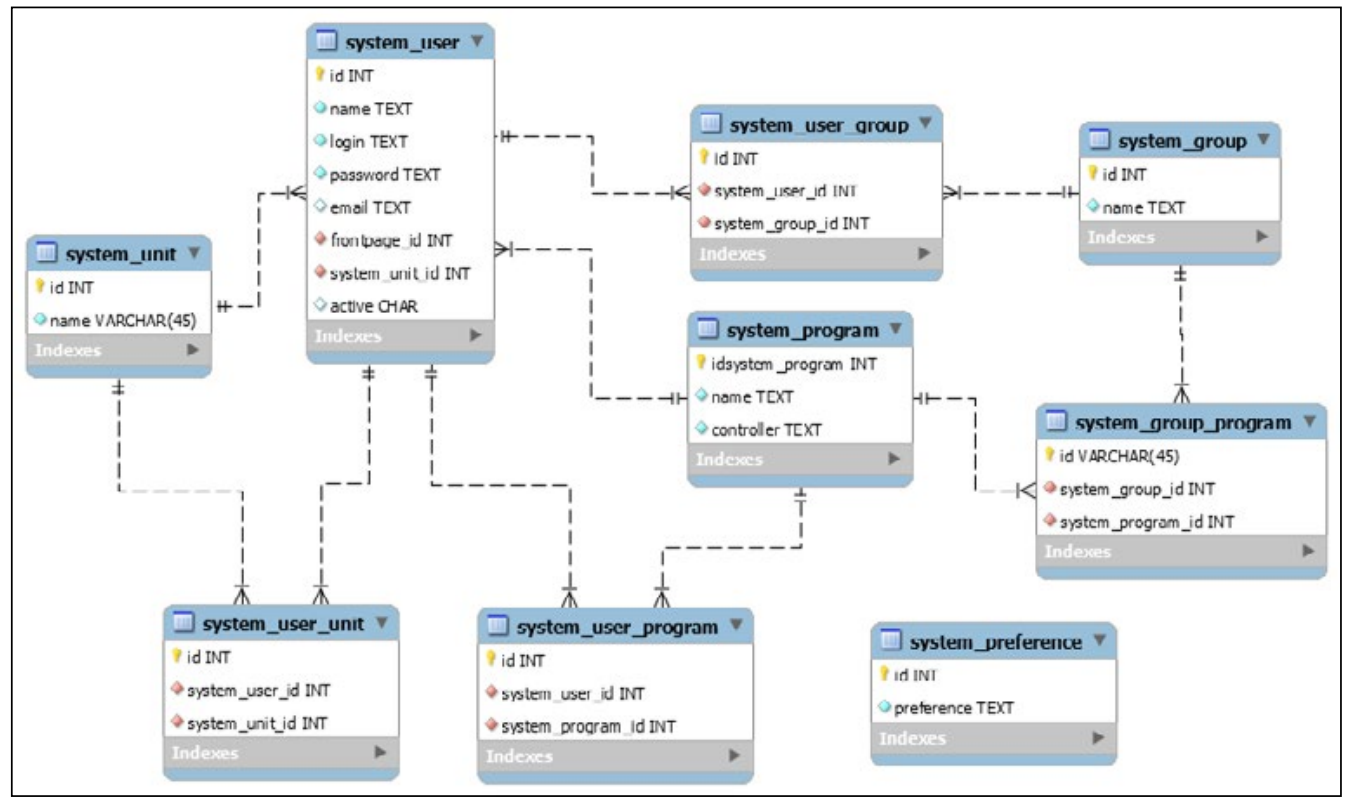

Fonte: Do autor (2020).

\subsection{Casos de uso}

A Figura 5 apresenta o diagrama de Casos de Uso da solução desenvolvida, ele foi criado buscando mostrar as principais funcionalidades do AutoM8. Neste diagrama é possível visualizar dois atores principais:

- Administrador, responsável pela manutenção dos cadastros principais de borda da aplicação e manutenção de permissões e usuários que utilizarão a ferramenta;

- Usuário, é responsável por controlar e executar as tarefas automatizadas nas estações clientes, manter cadastro dos dispositivos e rótulos dos mesmos, dos softwares, além de manter o cadastro dos scripts. 
Figura 5 - Modelo do diagrama de casos de uso do Sistema web



Fonte: Do autor (2020).

O sistema cliente, corresponde à aplicação implantada nas estações de rede gerenciadas pelo sistema web atuando de forma autônoma em conjunto com o webservice. Ele é responsável por manter registro do sistema operacional e endereço MAC do dispositivo cliente, e também pelas ações de requisitar uma nova tarefa, controlar e executar as tarefas no sistema operacional, criar arquivos executáveis, obter dependências das tarefas junto ao sistema web. A aplicação cliente mantém a estrutura de diretórios dos arquivos das tarefas no sistema operacional e enviar os 41 estados e logs da execução das tarefas ao web service, conforme pode ser visto no modelo de diagrama de casos na Figura 6. 
Figura 6 - Modelo do diagrama de casos de uso do sistema cliente

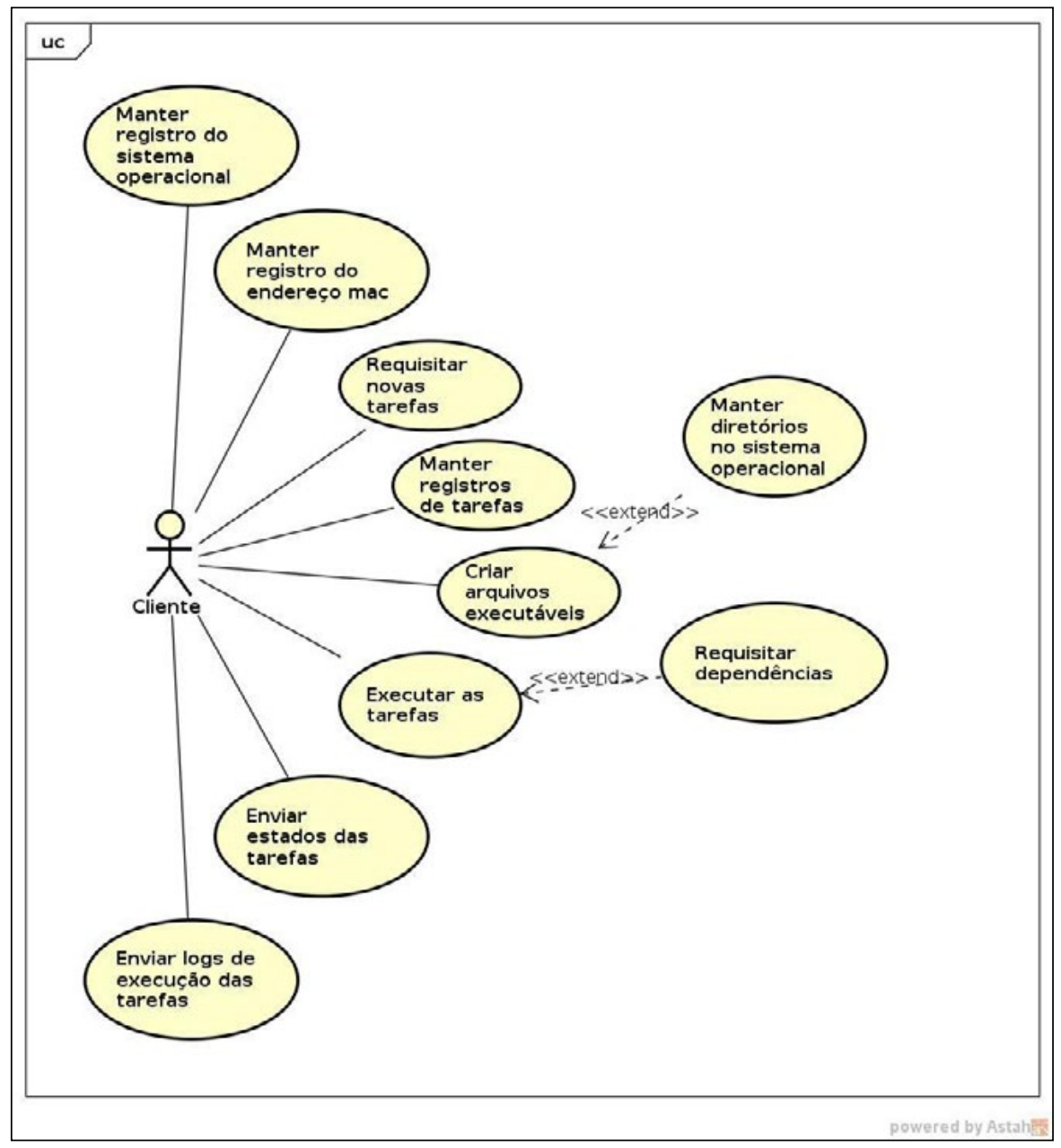

Fonte: Do autor (2020).

\subsection{Telas da solução}

Nesta seção são demonstradas as telas principais da solução desenvolvida no presente trabalho, denominada AutoM8.

A tela de criação de scripts, tem por principal atribuição manter o cadastro dos scripts. Nela estão dispostas as informações como nome do script, a descrição do que o script faz, o status do script, que pode ser "Produção", ou seja, script já testado para execução em lotes, "Modelo", sendo este um script de exemplo para reaproveitamento de código ou "Rascunho", ou seja, um esboço de um script. Os scripts podem possuir três formatos diferentes, seja um batch file ".bat", PowerShell Script ".ps1" ou ShellScript ".sh", além 
de poder vincular um software previamente cadastrado para realizar alguma ação, também permite adicionar uma observação sobre o script em questão e por fim criar o script em texto, como pode ser visto na Figura 7.

Figura 7 - Tela de criação do script

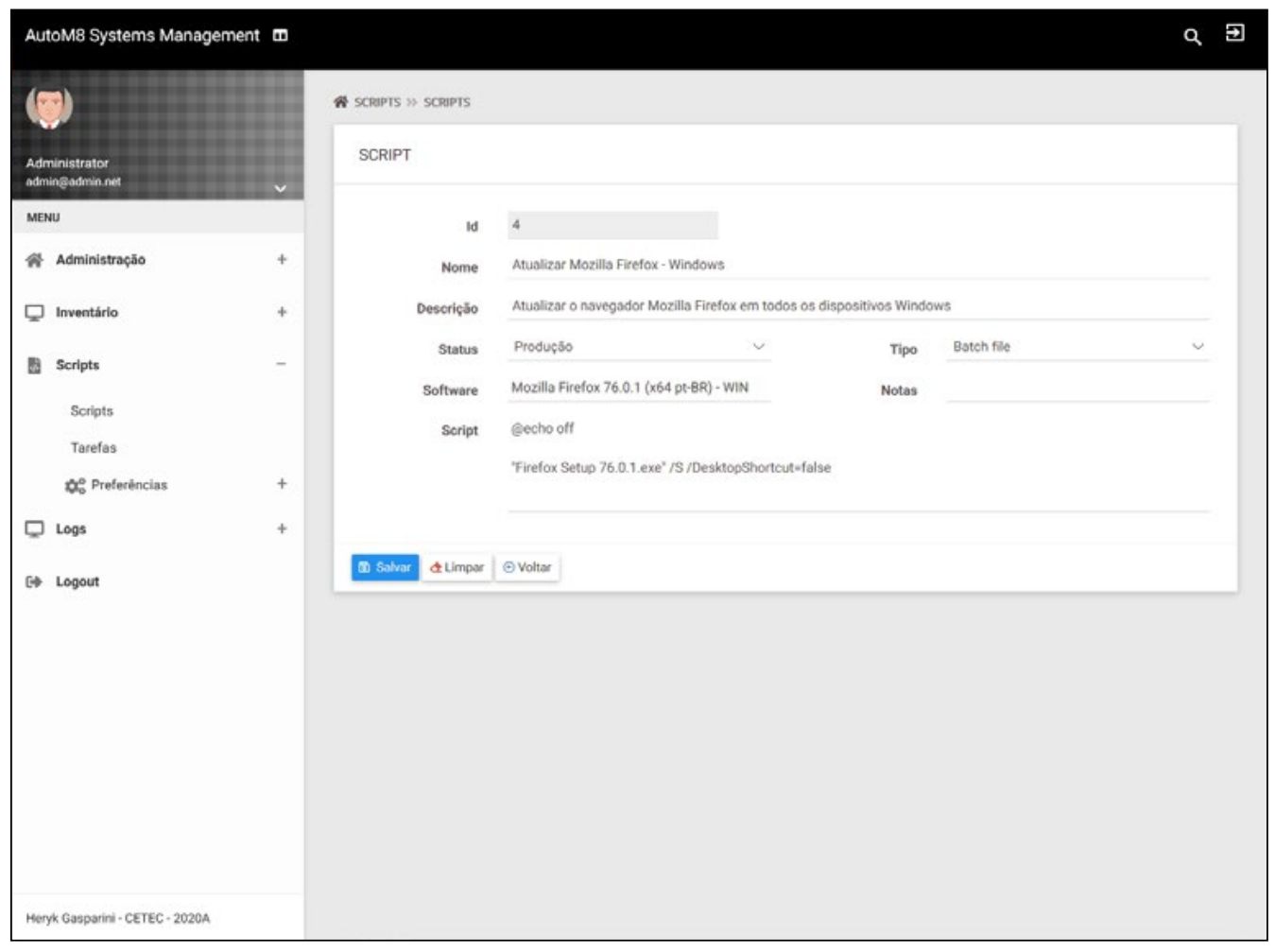

Fonte: Do autor (2020).

O script é um conjunto de instruções em código que executa funções para controle, configuração ou instalação de um determinado software operacional ou aplicativo. Os dois principais conjuntos de instruções são o Shell Script, pertencente às plataformas Unix e o PowerShell que integra as plataformas Windows da Microsoft. Na Figura 8, é apresentado um exemplo de script desenvolvido em PowerShell para realizar a instalação do aplicativo Mozilla Firefox em estações Windows. Na linha 3 o script inicia o processo de instalação definindo o diretório do instalador e o argumento "/S" indicando que a instalação será no modo Silent, ou seja, sem interação com o usuário. Na linha 7 é definido o tempo de espera até a próxima instrução. Na linha 11 o script irá remover todos os arquivos pertencentes ao instalador do aplicativo. 
Figura 8 - Exemplo de script em PowerShell

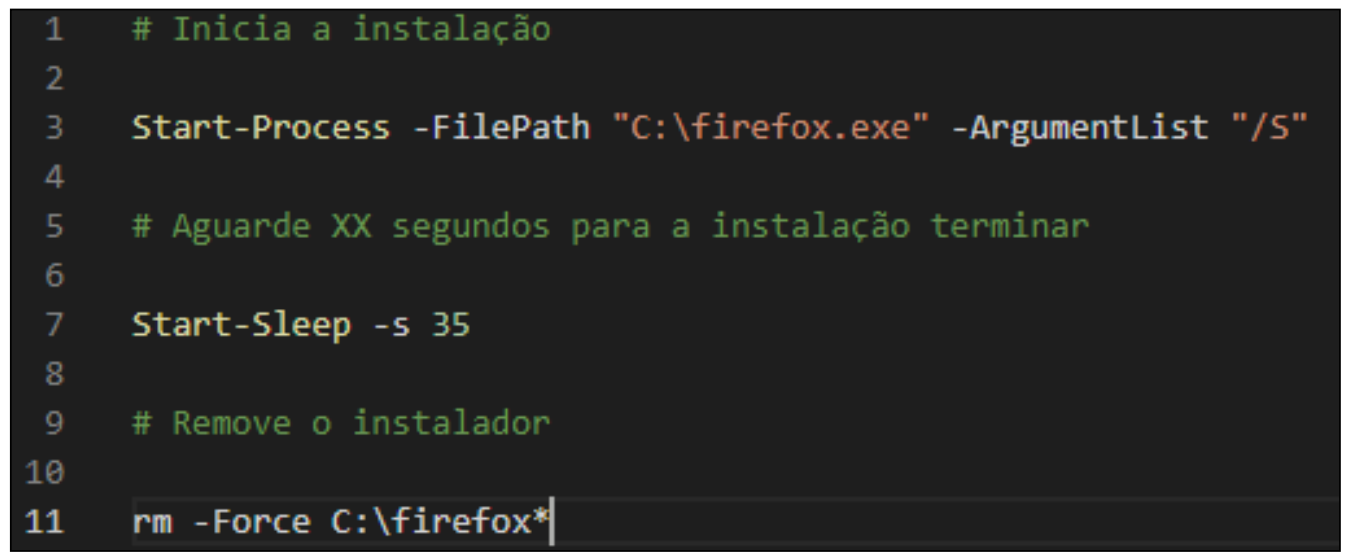

Fonte: Do autor (2020).

Na Figura 9, pode-se visualizar a tela da situação das tarefas de execução ou também pode ser compreendida como o resumo das execuções das tarefas, onde visualiza-se um filtro com os atributos da data criação e da conclusão, estado da tarefa, rótulo de dispositivos, dispositivo e descrição do script. Além da tabela com os registros das tarefas executadas, pode-se visualizar a descrição do script, a data e hora quando a tarefa foi criada, o dispositivo direcionado e o estado da tarefa em tempo real.

A aplicação cliente realiza a criação dos arquivos de scripts e os transforma em executáveis com base nas informações disponibilizadas pelo web service, após inicia o controle e a execução da tarefa no sistema operacional do cliente. Ao término da execução, o sistema cliente envia o detalhamento da situação da tarefa para o web service contendo informações do estado que a tarefa se encontra e de logs coletados, que por sua vez disponibiliza para a visualização no sistema web, como pode ser visto na Figura 10. 
Figura 9 - Tela de resumo de execução das tarefas



Fonte: Do autor (2020).

Figura 10 - Processos da solução AutoM8



Fonte: Do autor (2020). 


\subsection{Testes e análise dos resultados}

Para validar a solução AutoM8 utilizaram-se três Laboratórios de Informática pertencentes a Univates - Universidade do Vale do Taquari contendo um total de 81 computadores de diferentes hardwares e sistemas operacionais. Foram realizados dois testes em diferentes cenários com servidores de configuração de hardware distintos, além de classificar os testes em três diferentes categorias: baixa carga, ou seja, sem software; média carga, com tamanhos de softwares até $300 \mathrm{MB}$; e alta carga com tamanhos de software superior a $300 \mathrm{MB}$.

Realizou-se três diferentes testes com cenários distintos, o primeiro com um laboratório de informática contendo 31 estações simultâneas, o segundo com dois laboratórios de informática contendo 56 estações simultâneas e o último com três laboratórios contendo 81 estações de rede simultâneas.

Com os resultados obtidos nas tarefas podemos observar que a aplicação desenvolvida utilizando o Servidor 1 obteve pior desempenho nos diferentes cenários devido aos recursos de hardware serem inferiores ao Servidor 2 e a solução Quest KACE.

Quadro 1 - Comparativo de resultados

\begin{tabular}{|c|c|c|c|c|}
\hline Níveis & Tarefas & $\begin{array}{c}\text { Servidor 1 } \\
\text { AutoM8 }\end{array}$ & $\begin{array}{c}\text { Servidor 2 } \\
\text { AutoM8 }\end{array}$ & Quest KACE \\
\hline \multirow{2}{*}{$\begin{array}{c}\text { Baixa Carga } \\
\text { (sem software) }\end{array}$} & $\begin{array}{c}\text { Alterar senha perfil } \\
\text { administrador labs. }\end{array}$ & $97.02 \%$ & $99.40 \%$ & $99.40 \%$ \\
\cline { 2 - 5 } & $\begin{array}{c}\text { Remover atalhos } \\
\text { área de trabalho }\end{array}$ & $95.83 \%$ & $100 \%$ & $98.81 \%$ \\
\hline $\begin{array}{c}\text { Média Carga } \\
\text { (software até 300 } \\
\text { MB) }\end{array}$ & $\begin{array}{c}\text { Atualizar Mozilla } \\
\text { Firefox }\end{array}$ & $98.81 \%$ & $99.40 \%$ & $99.40 \%$ \\
\cline { 2 - 5 } & Instalar Blender & $96.43 \%$ & $98.81 \%$ & $98.21 \%$ \\
\hline $\begin{array}{c}\text { Alta Carga } \\
\text { (software superior } \\
\text { a 300MB) }\end{array}$ & $\begin{array}{c}\text { Instalar Autodesk } \\
\text { AutoCAD }\end{array}$ & $95.24 \%$ & $97.62 \%$ & $98.81 \%$ \\
\hline
\end{tabular}

Fonte: Do autor (2020).

Nas tarefas de baixa carga obteve-se resultados iguais utilizando a aplicação desenvolvida com o Servidor 2 e o ambiente Quest KACE, já nas tarefas média carga alcançou-se resultados superiores ao ambiente da solução Quest KACE utilizando a solução AutoM8 no Servidor 2.

No ambiente da solução consolidada Quest KACE obteve um resultado superior na tarefa com alta carga em relação ao AutoM8 utilizando o Servidor 2 em 1.81\% devido aos recursos de hardware do ambiente Quest KACE serem superior ao do Servidor 2 na solução de desenvolvida. Por fim, obteve-se 
resultados superiores e iguais nas tarefas de baixa e média carga utilizando o Servidor 2, apenas sendo inferior na tarefa com alta carga.

\section{CONSIDERAÇÕES FINAIS}

De acordo com os conceitos abordados no presente trabalho referenciando a governança da TI, gestão de recursos de TI, gerenciamento de redes de computadores e também comparando soluções de gerenciamento remoto conceituadas no mercado, resultou-se no desenvolvimento de uma nova solução.

O objetivo do desenvolvimento de uma nova solução buscou atender às funcionalidades de reutilizar os scripts das tarefas para a gestão, manutenção, atualização de sistemas operacionais e aplicativos de forma remota otimizando o processo de trabalho de profissionais e departamentos de TI nas organizações.

Por fim, com base nas informações dispostas no desenvolvimento da solução, bem como as tecnologias e métodos empregados, é possível afirmar que a solução é aplicável em ambientes de produção, validando-se o projeto com diferentes cenários nos Laboratórios de Informática da Univates chegou-se a números superiores em êxito de tarefas na comparação com uma solução já consolidada no mercado.

\section{REFERÊNCIAS}

ALBERTIN, Alberto Luiz; ALBERTIN, R. M. D. M. Tecnologia de informação e desempenho empresarial: as dimensões de seu uso e sua relação com os benefícios do negócio. 1. ed. São Paulo: Atlas, 2005. p. 150.

ASSIS, Célia Barbosa. Governança e gestão da tecnologia da informação: Diferenças na aplicação em empresas brasileiras. Dissertação de mestrado em Engenharia. Escola Politécnica da Universidade de São Paulo. São Paulo. 2011

AVALLE, Rodrigo P. Gerenciamento de Redes. 1996. Trabalho apresentado como requisito parcial para aprovação na Disciplina Teleinformática, Centro de Tecnologia - Escola de Engenharia, Universidade Federal do Rio de Janeiro, Rio de Janeiro, 1996. Disponível em: <https://www.gta.ufrj.br/grad/99_1/rodrigo/ger_redes.htm>. Acesso em: 13 out. 2019.

CARVALHO, T. C. M. D. B. Gerenciamento de redes: uma abordagem de sistemas abertos. 1. ed. São Paulo: Makron Books, 1993.

ITGI. COBIT 4.1. Disponível em: <http:/ / www.isaca.org/knowledge-center/ research/researchdeliverables/pages/cobit-4-1.aspx>. Acesso em: 12 out. 2019.

MARCONI, Marina de Andrade.; LAKATOS, Eva Maria. Fundamentos de Metodología Científica. 5. ed. São Paulo: Atlas S.A., 2003. 
NEVES, Miranilde Oliveira. A Importância da Investigação Qualitativa no Processo de Formação Continuada de Professores: Subsídios ao exercício da docência. Revista Fundamentos, v.2, n.1, 2015. Disponível em: <https:/ / revistas.ufpi.br/index.php/ fundamentos/article/view/3723/2186>. Acesso em: 16 jun. 2020.

MENDES, Douglas Rocha. Redes de Computadores: Teoria e Prática. 2. ed. [S.1.]: Novatec, 2015.

PICADA, Rodrigo Cassol. Governança de Tecnologia da Informação baseado na Metodologia COBIT: O caso de um banco privado brasileiro. Trabalho apresentado no XXVI Enegep, 2006, Fortaleza. Disponível em: <http:/ /www.ea.ufrgs.br/ professores/acgmacada/pubs/Governanca\%20TI\%20macada\%20rodrigo \%20 leonardo\%20guilherme\%20enegep\%202007.pdf>. Acesso em: 25 jun. 2020.

SILVA, Paulo Augusto Gonçalves da. ITIL - Biblioteca de Infraestrutura de TI: Uso das Boas Práticas na Aplicação de Software para Service Desk. 2009. 50f. Monografia (Tecnológo em Informática com Ênfase em Gestão de Negócios) - Faculdade de Tecnologia da Zona Leste, São Paulo, 2009.

SPEZIA, Jamiel. Sistema distribuído para monitorar o uso dos recursos de hardware e software em estações de trabalho GNU/LINUX. 2007. 157 f. Monografia - Curso de Engenharia da Computação, Univates, Lajeado - RS, 2007.

TANENBAUM, Andrew Stuart. Computer Networks. 4. ed. [S.1.]: Prentice Hall, 2002. Disponível em: <http:/ / www.vazzi.com.br/arquivos_moodle/Redes\%20de\%20 Computadores\%20-\%20Tanenbaum.pdf>. Acesso em: 13 out. 2019.

THOMPSON-FLÔRES, E. A. L. Governança corporativa no Brasil e o papel dos investidores institucionais. Tese (Doutorado) - Departamento de Engenharia Industrial - PUC-62 RJ, 2004. Disponível em: <https: / / www.maxwell.vrac.puc-rio.br/ colecao.php?strSecao=resultado\&nrSeq=5703@1>. Acesso em: 12 out. 2019.

WEILL, Peter; ROSS, Jeanne W. IT Governance: How Top Performers Manage IT Decision Rights for Superior Results. 1. ed. [S.1.]: Harvard Business Press, 2004. 